Neurosurg Focus 4 (6):Article 10, 1998

\title{
Practice parameters in adults with suspected or known supratentorial nonoptic pathway low-grade glioma
}

\section{MISSION STATEMENT}

In January 1994, the Guidelines and Outcomes Committee of the American Association of Neurological Surgeons (AANS) issued a charge to develop practice parameters to treat adult patients with low-grade glioma (LGG). This area of study was chosen because of a similar interest on the part of the American Academy of Neurology (AAN) and the controversy surrounding the management of such patients.

\section{METHODS}

The Low-Grade Glioma Guidelines Team members (hereafter referred to as the Team) were invited to participate by the Guidelines and Outcomes Committee of the AANS, which included five neurological surgeons, three neurologists, and two radiation oncologists. One Team member was elected Chair (a radiation oncologist), with two Cochairs (one neurological surgeon and one neurologist). Two members of the AANS Guidelines and Outcomes Committee and one member of the AAN Quality Standards Subcommittee served as advisors to the Team. The Team met approximately semiannually between January 1994 and April 1996. The following is an outline of the process leading to the completion of the practice parameters.

A MEDLINE search for literature published during the years 1966 to 1994 was made in which the main MeSH headings astrocytoma and oligodendroglioma were used, with the subheadings drug therapy, radiography, radiotherapy, surgery, and therapy. The MEDLINE search resulted in 2624 citations. In addition, a scientific citation search was made in which three articles from the peer-reviewed medical literature were used that Team members considered to be "classic." $[26,37,45]$ The scientific citation searches resulted in 181 citations. Team members reviewed the abstracts for each citation and chose 59 [1-59] for a more complete review based on the following criteria: original work published in the peer-reviewed literature; full manuscript (no abstracts); English language; and directly or indirectly addressing the natural history, survival, tumor recurrence, or quality of life of adult patients managed with observation (with or without a tissue diagnosis), biopsy, resection, or radiation therapy. Complete review consisted of reading and abstracting the materials, methods, and results sections of each citation using a standard form designed by the Team. In addition, the quality of the evidence for each citation was classified according to the following accepted criteria:[60]

Class I: Evidence provided by one or more well-designed, randomized, controlled clinical trials. 
Class II: Evidence provided by one or more well-designed clinical studies such as case control or cohort studies.

Class III: Evidence provided by expert opinions, nonrandomized historical controls, or case reports of one or more.

The 59 citations chosen for complete review were divided among Team members so that at least three individuals (one from each specialty) reviewed each one. Fifteen "key" citations were chosen to support the results and recommendations (that is, Practice Parameters), 14 of which were designated as Class III evidence,[2,13,17,23,26,27,33-35,38,43,48,57,59] and one Class I.[53] Evidence tables were generated using an accepted format that summarized the essential data from the key citations.[61] Based on these 15 citations; practice parameters were generated according to the following accepted definitions.[60]

Standards. These consist of generally accepted principles for patient management that reflect a high degree of clinical certainty (based on Class I evidence, or, when circumstances preclude randomized controlled clinical trials, overwhelming evidence from Class II studies that directly addresses the questions at hand or from decision analysis that directly addresses all the issues).

Guidelines. These are recommendations for patient management that may identify a particular strategy or range of management strategies and that reflect moderate clinical certainty (based on Class II evidence that directly addresses the issue, decision analysis that directly addresses the issue, or strong consensus of Class III evidence).

Practice Options/Advisories. These are other strategies for patient management for which there is unclear clinical certainty (based on inconclusive or conflicting evidence or opinion).

An initial draft of the practice parameters was written by the Team Chair and Cochairs based on the work done by the Team members. Following review and revision by the entire Team and its advisors, this current practice parameter was generated and is presented here. The next step in the process will be presentation to the AANS/Congress of Neurological Surgeons Joint Committee for the Assessment of Quality, the Joint Section on Tumors and the Boards of both organizations, the Quality Standards Subcommittee, Practice Committee, and Executive Board of the AAN, and the American Society for Therapeutic Radiology and Oncology (ASTRO) Executive Committee to obtain endorsement by these subspecialty organizations.

\section{BACKGROUND}

To provide the reader with basic epidemiological and natural history information about LGG as a framework for the management issues to be addressed by the Team, the following background section is summarized from the 59 citations selected for complete review.[1-59] The estimated annual incidence of pediatric and adult LGG in the United States is 1800 cases. The histological subtypes of LGG include pilocytic astrocytoma, diffuse fibrillary astrocytoma, oligodendroglioma, and oligoastrocytoma. Pilocytic astrocytoma represents a favorable subset of LGGs, occurring primarily in the cerebellum of children, although they may occur in the optic pathways and other supratentorial sites. There is little controversy related to the management of pilocytic astrocytoma. They are generally curable by means of gross-total resection. This report will focus on supratentorial nonoptic pathway nonpilocytic LGG (that is, diffuse fibrillary astrocytoma, oligodendroglioma, and oligoastrocytoma) occurring in adults.

The average patient age at diagnosis is 37 years. Approximately two-thirds of patients present with a 
seizure and in one-half the neurological exam is normal. Neuroimaging studies usually demonstrate a lobar, noncontrast enhancing-lesion that is poorly defined on computerized tomography (CT) and better delineated on $\mathrm{T}_{2}$-weighted magnetic resonance (MR) images. The presence of contrast enhancement on CT or MR imaging is not consistently associated with a higher incidence of tumor recurrence or a lower rate of patient survival. The median survival time in adults following tissue diagnosis is approximately 5 years (range 1-10 years) and is strongly influenced by age. Patients younger than 40 years of age are more likely to survive than those who are 40 years old or older. Tumor recurrence is defined in three ways: worsening of neurological symptoms or signs; enlargement of a nonenhancing lesion on a CT or MR imaging; or transformation to a more anaplastic histological subtype (defined on imaging by a new area of contrast enhancement or pathologically at the time of rebiopsy or reoperation). One-half to three-quarters of adult patients with LGG will suffer tumor recurrence and die of their disease, accounting for the survival rate beyond 10 years of approximately $25 \%$ (range 5-50\%). Survival time is influenced by histological tumor type, being longer for oligodendroglioma, intermediate for oligoastrocytoma, and shortest for diffuse fibrillary astrocytoma. There was consensus among members of the Team that the following issues, despite the controversy that surrounds them, are key to the management of adult patients who present with a seizure, have a normal neurological examination, and in whom an imaging study (CT or MR) demonstrates a supratentorial nonoptic pathway, nonenhancing lesion that is consistent with a nonpilocytic astrocytoma (that is, diffuse fibrillary astrocytoma, oligodendroglioma, or oligoastrocytoma): Should biopsy sampling be performed to obtain a tissue diagnosis? Should the patient be observed, with or without a tissue diagnosis? Should tumor resection be undertaken, subtotal, gross total, or at all? Should postoperative radiation therapy be administered?

Evidence can be found in the available medical literature to support any of these approaches. This report will conclude with several specific recommendations (practice parameters) developed from a critical, scientifically based analysis of the literature addressing these management issues.

\section{RESULTS}

\section{Biopsy for Tissue Diagnosis}

There were two articles[22,59] in which the accuracy of an imaging diagnosis of LGG was addressed based on biopsy sampling in adult patients who presented with a seizure, were neurologically intact, and had a supratentorial nonoptic pathway nonenhancing lesion on a CT or MR image presumed to be a LGG. Of 55 patients in the combined series, $36(65 \%)$ had confirmation of a LGG, $16(30 \%)$ had an anaplastic astrocytoma, and three (5\%) had a benign process (two gangliogliomas, one encephalitis). No biopsy-associated morbidity or mortality was reported in either series.

\section{Observation With or Without a Tissue Diagnosis}

There were articles in which the natural history (survival) of patients who were observed with or without a tissue diagnosis was addressed. Recht, et al.,[36] compared the survival of one group of 26 patients with a presumed (imaging based) diagnosis of LGG who were observed with another group of 20 patients in whom a tissue diagnosis was made, which was followed by therapy consisting of further surgery or surgery plus radiation therapy. Possible selection biases explaining why patients were chosen for observation rather than treatment were not presented. Although $58 \%$ of patients in the observation group developed recurrence, median survival times were comparable ( 7 years) between the two groups.[34] Franzini, et al.,[12] reported a median survival time of 3 years for 70 patients who were observed following biopsy for LGGs in the thalamus and basal ganglia.[13] 
Resection. There were seven articles presenting survival comparisons of patients who underwent gross-total or radical subtotal resection compared with subtotal resection or biopsy. Three articles reported a statistically significant ( $\left.\mathrm{p}^{3 / 4} 0.05\right)$ survival benefit with more aggressive surgical resection, $[17,33,34]$ whereas there were articles in which there was no statistically significant $(p>0.05)$ survival difference according to the degree of surgical resection.[35,46,48,59] Although in one of these series,[59] the survival differences were suggestive of benefit ( $p>0.05$ and $<0.10)$. These seven articles are summarized in Table 1.

\begin{tabular}{|c|c|c|c|c|}
\hline \multicolumn{5}{|c|}{$\begin{array}{c}\text { TABLE } 1 \\
\text { SURYMaL IN SURGKAL RESECTION OF LOW-GRADE GLIOMAS }\end{array}$} \\
\hline \multirow[b]{2}{*}{ Authors \& Year } & \multirow[b]{2}{*}{$\begin{array}{l}\text { Extent of } \\
\text { Resection }\end{array}$} & \multirow[b]{2}{*}{$\begin{array}{l}\text { No. of } \\
\text { Patients }\end{array}$} & \multicolumn{2}{|c|}{ Survival } \\
\hline & & & 5 -Year $[\%]$ & $\begin{array}{l}\text { Mean' } \\
\text { Medan (yrs) }\end{array}$ \\
\hline Janny, et al., 1994 & gross total & 10 & 88 & - \\
\hline \multirow{3}{*}{ North, et al., 1990} & $\begin{array}{l}\text { Sulotiat inopsy } \\
\text { gross total }\end{array}$ & $\begin{array}{r}22 \\
6\end{array}$ & $\begin{array}{l}57 \\
85\end{array}$ & - \\
\hline & subtotil & 6 & 64 & - \\
\hline & gross & 9 & 43 & - \\
\hline \multirow{3}{*}{ Philippon, et al., 1993} & gross total & 45 & 80 & - \\
\hline & subtotal & 95 & 50 & - \\
\hline & tiopsy & 39 & 45 & - \\
\hline \multirow[t]{2}{*}{ Piepmeier, 1987} & gross total & 23 & - & 8.12 \\
\hline & subtotal & 22 & - & 7.08 \\
\hline \multirow{2}{*}{ Shaw, et al., 1989} & bopsy & 13 & 52 & 5.88 \\
\hline & tionsy & 103 & 52 & $\begin{array}{l}- \\
-\end{array}$ \\
\hline \multirow[t]{2}{*}{ Shitamoto, et al., 1993} & extensive & 15 & 64 & - \\
\hline & nonextensive & 86 & 59 & - \\
\hline
\end{tabular}

These seven articles are limited by a number of problems, such as the inclusion of patients in the pre-CT/MRI era (dated back as far as the 1950s), uncertain possible selection biases explaining why patients were chosen for more rather than less aggressive resection, dependence on the neurological surgeon's assessment alone rather than including postoperative imaging studies to determine the degree of surgical resection, small patient numbers in the various treatment groups, and lack of multivariate analyses that would take any extraneous prognostic variables into account. Another article reported outcomes other than survival, including tumor recurrence and anaplastic transformation as a function of an imaging-based determination of preoperative compared with postoperative tumor volumes in 53 patients with hemispheric LGG who underwent resection guided by cortical mapping.[2] The incidence of recurrence and the likelihood of anaplastic transformation were proportional to the preoperative and postoperative tumor volumes, whereas the time to recurrence was inversely related to tumor volumes.

\section{Radiation Therapy}

There were six articles in which survival comparisons of patients were presented who received postoperative radiation therapy compared with those who did not. Two articles found a statistically significant survival benefit with the use of radiation, $[45,48]$ whereas four did not.[17,34,35,59] Five of these articles reported specific survival data and are summarized in Table 2. 


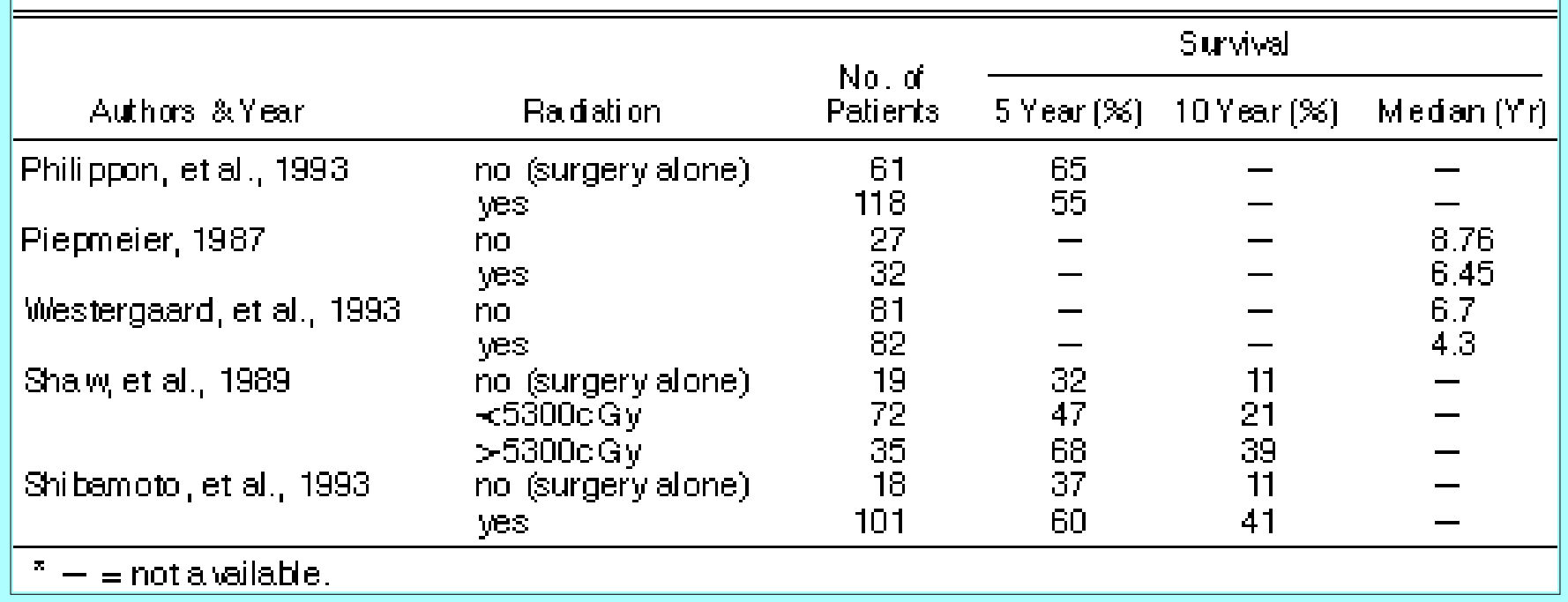

One of the articles[34] did find a significant survival benefit in the subset of patients older than 40 years of age who underwent subtotal resection or biopsy followed by radiation therapy. In another article[57] an increase was observed in the median time to anaplastic transformation, from 3.7 to 5.4 years, with the addition of postoperative radiation therapy compared with surgery alone. Once again, these data are limited by the same set of problems mentioned previously for the citations addressing the issue of resection. Another citation prospectively compared neuropsychological function in adult patients with supratentorial low-grade glioma, 20 who received postoperative radiation therapy and 20 who did not, with a group of 20 control patients who did not have brain tumors. Neuropsychological test scores were lower in the two groups who had LGG compared with the control group. There were no significant differences in test scores between the LGG patients undergoing radiation treatment and those who did not, leading the authors to conclude that it was the disease, rather than radiation, which adversely affected the brain function of the study patients.[53]

\section{RECOMMENDATIONS}

Based on a critical analysis of the available evidence of therapeutic effectiveness, which is essentially all Class III, it became clear that there were two separate pathways that could be followed in caring for these patients. There was evidence to suggest that patients could be observed, with or without biopsy, until a point in the progression of their disease when they became more symptomatic, or their scans indicated significant growth. There was also evidence that would support treatment, and if treatment was to be undertaken, a biopsy should be performed to verify the diagnosis of LGG. Table 3 summarizes the practice parameters offered for adult patients who present with a seizure, are neurologically intact, and have an imaging study (CT or MR) that demonstrates a supratentorial nonoptic pathway, nonenhancing lesion that is consistent with a diffuse fibrillary astrocytoma, oligodendroglioma, or oligoastrocytoma. 
TABLE 3

Evidence-Based Recommendations for the Treatment of Low-Girade Glioma

\begin{tabular}{|c|c|c|c|}
\hline $\begin{array}{l}\text { Maragenent } \\
\text { Issue }\end{array}$ & Evidence & $\begin{array}{l}\text { Quality of } \\
\text { Evidence }\end{array}$ & $\begin{array}{c}\text { Stmmary } \\
\text { Recommendation }\end{array}$ \\
\hline $\begin{array}{l}\text { biopsy (prior to } \\
\text { active treatment) }\end{array}$ & $\begin{array}{l}\text { there is no diagnostic test which is sufficient to } \\
\text { act as a surrogate for the "gold standard" } \\
\text { (tissue diagnosis), with } 35 \% \text { of patients in two } \\
\text { studies having al temative diagnoses when } \\
\text { presumed to have LGG on imaging }\end{array}$ & Cass I & Standard \\
\hline $\begin{array}{l}\text { tiopsty (prior to ob- } \\
\text { servation alone) }\end{array}$ & $\begin{array}{l}\text { al though there is evide noe that MR or CT im - } \\
\text { aging cannot attain }=65 \% \text { positive predictive } \\
\text { value, and there fore biopsy is the diagnostic } \\
\text { test of choice, there is no evidenoe that it is } \\
\text { harmful to patients to obser 'we whout tiopsy }\end{array}$ & Cass III & Option \\
\hline observation & $\begin{array}{l}\text { in two series, patients obser wed after tissue } \\
\text { diagnosis had survi wal rates com parable to } \\
\text { patients from other series receiving radia- } \\
\text { tion therapy }\end{array}$ & Cass III & Option \\
\hline resection & $\begin{array}{l}\text { seien series reported better survival for pa- } \\
\text { tients undergoing resection; in four, the } \\
\text { survival differences mere significant; sur- } \\
\text { wival was proportional to the degree of } \\
\text { surgical resection }\end{array}$ & Cass III & Option \\
\hline radiation therapy & $\begin{array}{l}\text { two of six series reported significantly better } \\
\text { survival for patients undergoing radiation } \\
\text { therapy; in three of the other four series, } \\
\text { survival mas nonsignificant for nonradiated } \\
\text { patients }\end{array}$ & Cass III & Option \\
\hline
\end{tabular}

\section{OVERVIEW OF CONTEMPORARY RESEARCH AND RECOMMENDATIONS FOR FUTURE RESEARCH}

At the present, there are a number of recently completed, ongoing, and planned randomized, controlled clinical trials for adult patients with a supratentorial nonoptic pathway low-grade astrocytoma, oligodendroglioma, or oligoastrocytoma. The European Organization for the Research and Treatment of Cancer (EORTC) has sponsored two trials. In the first, patients were randomized to groups that received low-dose (45 Gy) or high-dose radiation $(59.4 \mathrm{~Gy})$ to localized treatment fields. In the second EORTC trial, patients are being randomized between observation (radiation therapy delayed until the time of recurrence) and radiation therapy (54Gy). The University of Toronto is developing a trial similar to the second EORTC trial. The North Central Cancer Treatment Group, in conjunction with the Eastern Cooperative Oncology Group and the Radiation Therapy Oncology Group (RTOG), recently completed a low- compared with high-dose radiation therapy trial, in which patients received either 50.4 Gy or 64.8 Gy to localized treatment fields. Last, the RTOG is developing a risk factor-based controlled clinical trial. Patients considered to be "low risk" (age $<40$ years who undergo gross-total resection) will be observed, whereas high risk patients (age $>40$ or less than gross-total resection) will be randomized to radiation therapy with or without postradiation chemotherapy. This study will include a prospective comparison of the extent of surgical resection between the neurological surgeon's operative assessment and findings of the postoperative MR image.

\section{DISCLAIMER}

These practice parameters are provided as an educational service by members of the AANS, AAN, and 
ASTRO. These sponsoring organizations have not, at this juncture, endorsed these guidelines. The guidelines are based on a critical analysis of the available evidence in the medical literature. They are not intended to include all possible clinical scenarios in patients with LGG. Specifically, they do not address recommendations in patients with pilocytic astrocytoma, children, and adult patients who present with infratentorial or optic pathway LGG, symptoms other than seizure, are not neurologically intact (do not have a normal neurological examination), or have a contrast-enhancing lesion on their imaging study (CT or MR). They do not address and are not intended to exclude other alternative treatments. The authors representing the AANS, AAN, and ASTRO recognize that patient care decisions are the prerogative of the patients and the physician(s) caring for the patient and must be individualized based on all of the circumstances involved.

\section{TEAM MEMBERS AND ADVISORS}

Edward Shaw, M.D. (Chair, Radiation Oncology)

Mark Bernstein, M.D. (Cochair, Neurological Surgery)

Lawrence Recht, M.D. (Cochair, Neurology)

Stephen Ashway, M.D.

Mark Camel, M.D.

Robert Florin, M.D. (Advisor, AANS)

Stephen Haines, M.D.

Brian O'Neill, M.D.

Jack Rock, M.D.

Jay Rosenberg, M.D. (Advisor, AAN)

Mark Rosenblum, M.D.

Michael Shea, M.D.

Beverly Walters, M.D. (Advisor, AANS)

\section{ACKNOWLEDGMENTS}

The team members wish to acknowledge the administrative assistance of the following individuals: Mrs. Diane Christie (Mayo Clinic), Mrs. Pam Cregger (Bowman Gray School of Medicine), Mrs. Joanne Okagaki (AAN), Mrs. Chris Phillips (AANS), and Mrs. Joyce Cook (The Miriam Hospital).

\section{References}

1. Ayoubi S, Walter PH, Naik S, et al: Audit in the management of gliomas. Br J Neurosurg 7:61-70, 1993

2. Berger MS, Deliganis AV, Dobbins J, et al: The effect of extent of resection on recurrence in patients with low-grade cerebral hemisphere gliomas. Cancer 75:1784-1791, 1994

3. Berger MS, Ghatan S, Haglund MM, et al: Low-grade gliomas associated with intractable epilepsy: seizure outcome utilizing electrocorticography during tumor resection. J Neurosurg 79:62-69, 1993

4. Boon PA, Williamson PD, Fried I, et al: Intracranial, intraaxial, space-occupying lesions in patients with intractable partial seizures: an anatomoclinical, neuropsychological, and surgical correlation. 
5. Brotchi J, Baleriauz D, Deleclusse F: MRI and the surgical treatment of low-grade gliomas, in Chafel M, Dareel F, Pecker J (eds): Brain Oncology. Dordcecht, The Netherlands: Martinus Nijhoff, 1987

6. Cascino GD, Kelly PJ, Sharbrough FW, et al: Long-term follow-up of stereotactic lesionectomy in partial epilepsy: predictive factors and electroencephalographic results. Epilepsia 33:639-644, 1992

7. Cohadon F, Aouad N, Rougier A, et al: Histologic and nonhistologic factors correlated with survival time in supratentorial astrocytic tumors. J Neurooncol 3:105-111, 1985

8. Eyre HJ, Corlwey JJ, Townsend JJ, et al: A randomized trial of radiotherapy versus radiotherapy plus CCNU for incompletely resected low-grade gliomas: a Southwest Oncology Group Study. J Neurosurg 78:909-914, 1993

9. Fadul C, Wood J, Thaler H, et al: Morbidity and mortality of craniotomy for excision of supratentorial gliomas. Neurology 38:1374-1379, 1988

10. Fazekas JT: Treatment of grades I and II brain astrocytomas. The role of radiotherapy. Int J Radiat Oncol Biol Phys 2:661-666, 1977

11. Francavila TL, Miletich RS, Di Chiro G, et al: Positron emission tomography in the detection of malignant degeneration of low-grade gliomas. Neurosurgery 24:1-5, 1989

12. Franzini A, Cajola L, Allegranza A: Low-grade glial tumors in basal ganglia and thalamus: natural history and biological reappraisal. Neurosurgery 35:817-831, 1994

13. Fried I, Kim JH, Spencer DD: Limbic and neocortical gliomas associated with intractable seizures: a distinct clinicopathological group. Neurosurgery 34:815-824, 1994

14. Garcia DM, Fulling KH, Marks JE: The value of radiation therapy in addition to surgery for astrocytomas of the adult cerebrum. Cancer 55:919-927, 1985

15. Hutton JL, Smith DF, Sandemann D, et al: Development of prognostic index for primary supratentorial intracerebral tumours. J Neurol Neurosurg Psychiatry 55:271-274, 1992

16. Janny P, Cure H, Mohr M, et al: Low grade supratentorial astrocytomas. Management and prognostic factors. Cancer 73:1937-1945, 1994

17. Kallio M: Therapy and survival of adult patients with intracranial glioma in a defined population. Acta Neurol Scand 81:541-549, 1990

18. Kelly PJ, Daumas-Duport C, Scheithauer BW, et al: Stereotactic histologic correlations of computed tomography-and magnetic resonance imaging-defined abnormalities in patients with glial neoplasms. Mayo Clin Proc 62:450-459, 1987

19. Kirkpatrick PJ, Honavar M, Janota I, et al: Control of temporal lobe epilepsy following en bloc resection of low-grade tumors. J Neurosurg 78:19-25, 1993

20. Kleinberg L, Wallner K, Malkin MG: Good performance status of long-term disease-free survivors of intracranial gliomas. Int J Radiat Oncol Biol Phys 26:129-133, 1993 
21. Koivukangas J, Koivukangas P: Treatment of low-grade cerebral astrocytoma: new methods and evaluation of results. Ann Clin Res 18:115-124, 1986

22. Kondziolka D, Lunsford LD, Martrinez AJ: Unreliability of contemporary neurodiagnostic imaging in evaluating suspected adult supratentorial (low-grade) astrocytoma. J Neurosurg 79:533-536, 1993

23. Kotwica Z, Zawirski M, Papierz W, et al: Clinical course and surgical results in supratentorial low-grade gliomas. Zntbl Neurochir 48:252-255, 1987

24. Krouwer JGJ, Davis RL, Silver P, et al: Gemistocytic astrocytomas: a reappraisal. J Neurosurg 74:399-406, 1991

25. Laws ER Jr, Taylor WF, Clifton MB, et al: Neurosurgical management of low-grade astrocytoma of the cerebral hemispheres. J Neurosurg 61:665-673, 1984

26. Leibel SA, Sheline GE, Wara WM, et al: The role of radiation therapy in the treatment of astrocytomas. Cancer 35:1551-1557, 1975

27. Lunsford LD, Somaza S, Kondziolka D, et al: Survival after stereotactic biopsy and irradiation of cerebral nonanaplastic, nonpilocytic astrocytoma. J Neurosurg 82:523-529, 1995

28. Marsa GW, Goffinet DR, Rubenstein LJ, et al: Megavoltage irradiation in the treatment of gliomas of the brain and spinal cord. Cancer 36:1681-1689, 1975

29. McCormack BM, Miller DC, Budzilovich GN, et al: Treatment and survival of low-grade astrocytoma in adults--1977-1988. Neurosurgery 31:636-642, 1992

30. Medberry CA III, Straus KL, Steinberg SM, et al: Low-grade astrocytomas: treatment results and prognostic variables. Int J Radiat Oncol Biol Phys 15:837-841, 1988

31. Mirabell R, Balart J, Matias-Guiu X, et al: Radiotherapy for supratentorial low-grade gliomas: results and prognostic factors with special focus on tumour parameters. Radiother Oncol 27:112-116, 1993

32. North CA, North RB, Epstein JA, et al: Low-grade cerebral astrocytomas. Survival and quality of life after radiation therapy. Cancer 66:6-14, 1990

33. Philippon JH, Clemenceau SH, Faushon FH, et al: Supratentorial low-grade astrocytomas in adults. Neurosurgery 32:554-559, 1993

34. Piepmeier JM: Observations on the current treatment of low-grade astrocytic tumors of the cerebral hemispheres. J Neurosurg 67:177-181, 1987

35. Rajan B, Pickuth D, Ashley S, et al: The management of histologically unverified presumed cerebral gliomas with radiotherapy. Int J Radiat Oncol Biol Phys 28:405-413, 1993

36. Recht LD, Lew R, Smith TW: Suspected low-grade glioma: is deferring treatment safe? Ann Neurol 31:431-436, 1992

37. Reichenthal E, Feldman Z, Cohen MI, et al: Hemispheric supratentorial low-grade astrocytoma. Neurochirurgia 35:18-22, 1992

38. Rogers LR, Morris HH, Lupica K: Effect of cranial irradiation on seizure frequency in adults with 
low-grade astrocytoma and medically intractable epilepsy. Neurology 43:1599-1601, 1993

39. Rutten EHJM, Kazem I, Slooff JL, et al: Postoperative radiation therapy in the management of brain astrocytomata--retrospective study of 142 patients. Int J Radiat Oncol Biol Phys 7:191-195, 1981

40. Satoyuki I, Chandler KL, Prados MD, et al: Proliferative potential and prognostic evaluation of low-grade astrocytomas. J Neurooncol 19:1-9, 1994

41. Scanlon PW, Taylor WF: Radiotherapy of intracranial astrocytomas: analysis of 417 cases treated from 1960 through 1969. Neurosurgery 5:301-308, 1979

42. Schifter T, Hoffman JM, Hanson MW, et al: Serial-FDG-PET studies in the prediction of survival in patients with primary brain tumors. J Comp Assist Tomography 17:509-516, 1993

43. Shaw EG, Daumas-Duport C, Scheithauer BW, et al: Radiation therapy in the management of low-grade supratentorial astrocytomas. J Neurosurg 70:853-861, 1989

44. Shaw EG, Scheithauer BW, Gilbertson DT, et al: Postoperative radiotherapy of supratentorial low-grade gliomas. Int J Radiat Oncol Biol Phys 16:663-668, 1989

45. Shaw EG, Scheithauer BW, O'Fallon JR, et al: Mixed oligoastrocytomas: a survival and prognostic factor analysis. Neurosurgery 34:577-582, 1994

46. Sheline GE: Radiation therapy of brain tumors. Cancer 39:873-881, 1997

47. Shibamoto Y, Kitakabu Y, Takahashi M, et al: Supratentorial low-grade astrocytoma. Cancer 72:190-195, 1993

48. Silverman C, Marks JE: Prognostic significance of contrast enhancement in low-grade astrocytomas of the adult cerebrum. Radiology 139:211-213, 1981

49. Smith DF, Hutton JL, Sandeman D, et al: The prognosis of primary intracerebral tumors presenting with epilepsy: the outcome of medical and surgical management. J Neurol Neurosurg Psychiatry 54:915-920, 1991

50. Soffietti R, Chiö A, Giordana MT, et al: Prognostic factors in well-differentiated cerebral astrocytomas in the adult. Neurosurgery 24:686-692, 1989

51. Steiger HJ, Markwalder RV, Seiler RW, et al: Early prognosis of supratentorial grade 2 astrocytomas in adult patients after resection of stereotactic biopsy. Acta Neurochir 106:99-105, 1990

52. Taphoorn MJB, Schiphorst AK, Snoek FJ, et al: Cognitive functions and quality of life in patients with low-grade gliomas: the impact of radiotherapy. Ann Neurol 36:48-54, 1994

53. Trojanowski T, Peszynski J, Turowski K, et al: Quality of survival of patients with brain gliomas treated with postoperative CCNU and radiation therapy. J Neurosurg 70:18-23, 1989

54. Vech CJ: Effect of age on treatment decision in low-grade glioma. J Neurol Neurosurg Psychiatry 56:1259-1264, 1993

55. Vertosick FT Jr, Selker RG, Arena VC: Survival of patients with well-differentiated astrocytomas diagnosed in the era of computed tomography. Neurosurgery 28:496-501, 1991 
56. Weir B, Grace M: The relative significance of factors affecting postoperative survival in astrocytomas, grades one and two. Can J Neurol Sci 3:47-50, 1976

57. Westergaard L, Gjerris F, Klinken L: Prognostic parameters in benign astrocytomas. Acta Neurochir 123:1-7, 1993

58. Whitton AC, Bloom HJG: Low grade glioma of the cerebral hemispheres in adults: a retrospective analysis of 88 cases. Int J Radiat Oncol Biol Phys 18:783-786, 1990

59. Wilden JN, Kelly PJ: CT computerized stereotactic biopsy for low density CT lesions presenting with epilepsy. J Neurol Neurosurg Psychiatry 50:1302-1305, 1987

Citations Chosen for Complete Review

\section{Other Citations}

60. Eddy DM: Designing a practice policy. Standards, guidelines, and options. JAMA 263:3077-3084, 1990

61. U.S. Department of Health and Human Services, Public Health Service, Agency for Health Care Policy and Research: Acute Low-Back Problems in Adults. Clinical Practice Guideline Number 14. Rockville, MD, Publication No. 95-0642, 12-94 